\title{
A. LOS DERECHOS FUNDAMENTALES Y LIBERTADES PÚBLICAS EN LA CONSTITUCIÓN COLOMBIANA DE 1991
}

\author{
PEDRO JOSÉ GONZALEZ-TREVIJANO SÁNCHEZ \\ Profesor Titular de Derecho Constitucional
}

Facultad de Derecho de la Universidad Complutense de Madrid

y

EDUARDO MARTÍNEZ HERNÁNDEZ

Profesor Titular Interino de Derecho Constitucional

Facultad de Derecho de la Universidad Complutense de Madrid 
SUMARIO

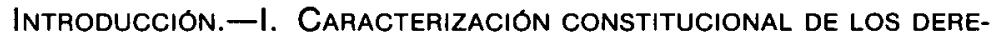
CHOS FUNDAMENTALES Y LIBERTADES PÚBLICAS.-1. Sus rasgos generales más sobresalientes. 2. Garantias de los Derechos Fundamentales y libertades públicas. 


\title{
A. LOS DERECHOS FUNDAMENTALES $Y$ LIBERTADES PÚBLICAS EN LA CONSTITUCIÓN COLOMBIANA DE 1991
}

\author{
POR \\ PEDRO JOSÉ GONZALEZ-TREVIJANO SÁNCHEZ \\ Profesor Titular de Derecho Constitucional \\ Facultad de Derecho de la Universidad Complutense de Madrid \\ y \\ EDUARDO MARTÍNEZ HERNANDEZ \\ Profesor Titular Interino de Derecho Constitucional \\ Facultad de Derecho de la Universidad Complutense de Madrid
}

\section{INTRODUCCION}

La Constitución de 1991 que ha derogado la anterior Carta constitucional de 1886 se nos presenta, a los efectos de la siguiente reflexión sobre el Sistema de Derechos Fundamentales y Libertades Públicas reconocidos y garantizados en el nuevo marco constitucional, como un proyecto feliz de establecer y afianzar en Colombia un verdadero Estado de Derecho. Estado de Derecho que, enunciado ya en el Texto constitucional en su mismo artículo primero - Colombia es un Estado social de Derecho...-, no se puede entender en la modernidad sin una referencia necesaria a los derechos fundamentales. $Y$ ello es asi, tanto desde sus primeras manifestaciones en las Declaraciones de Derechos del siglo XVIII, como en las diferentes formulaciones doctrinales más destacadas que de dicha noción político-constitucional se han elaborado. Basta en este sentido con recor- 
dar el artículo 16 de la Declaración Francesa de Derechos del Hombre y del Ciudadano de 26 de agosto de 1789 - «Toda sociedad en la cual la garantía de los derechos no está asegurada ni la separación de poderes establecida, no tiene Constitución»-, la caracterización que hacia la Constitución de Massachusetts de 1790, en cuanto gobierno de las leyes y no de los hombres, o las primigenias construcciones doctrinales de Von Mohl en 1832 o de Max Weber, más tarde, al enunciar su teoría de la legitimidad racional. Un Estado de Derecho, en suma, en el que «los derechos fundamentales no aparecen como concesiones, sino como el corolario de la soberanía popular, a través de cuyo principio de ley no sólo implica un deber, sino también un derecho para el individuo" ?.

Examinemos, pues, la caracterización y contenido que de los derechos fundamentales y libertades públicas realiza la Constitución de 1991.

\section{CARACTERIZACION CONSTITUCIONAL DE LOS DERECHOS FUNDAMENTALES Y LIBERTADES PÜBLICAS}

\section{Sus rasgos generales más sobresalientes}

Rasgos generales de los derechos y libertades públicas amparados y tutelados en la Constitución colombiana de 1991 que podemos definir y ordenar del siguiente modo:

1. En primer término se trata de una Constitución que aparece con vocación de establecer un auténtico régimen constitucional, con la pretensión de fijar un marco político-constitucional de convivencia basado en relaciones de igualdad formal y real entre los distintos ciudadanos. Derechos y libertades fundamentales que se presentan, de este modo, no sólo como una garantia juridico formal, sino además como una efectiva realización material, que superando los tiempos de la concepción decimonónica del Estado Liberal hay que entender en la actualidad bajo la forma del Estado Social de Derecho ${ }^{2}$. A este respecto, el artículo $1 .^{\circ}$ no puede ser más esclarecedor: "Colombia es un Estado Social de Derecho, organizado en forma de

1 Pérez luño: Los Derechos Humanos, Sevilla 1979, p. 29.

2 Sobre dicha doble naturaleza de los derechos y las libertades fundamentales en el Estado de Derecho, ver, por ejemplo, Ellas DIAZ: Estado de Derecho y Sociedad Democrática, 5. ${ }^{a}$, Madrid 1973, p. 29. 
República... fundada en el respeto de la dignidad humana, en el trabajo y la solidaridad de las personas que la integran y en la prevalencia del interés general».

Caracterización del Estado colombiano en cuanto Estado Social de Derecho que queda también ya apuntado en el mismo Preámbulo de la Constitución: «... asegurar a sus integrantes la vida, la convivencia, el trabajo, la justicia, la igualdad, el conocimiento, la libertad y la paz, dentro de un marco jurídico, democrático y participativo que garantice un orden politico, económico y social justo, y comprometido a impulsar la integración de la comunidad latinoamericana». En la misma linea el artículo $2 .^{\circ}$ manifiesta: «Son fines esenciales del Estado: servir a la comunidad, promover la prosperidad general y garantizar la efectividad de los principios, derechos y deberes consagrados en la Constitución, ...asegurar la convivencia pacífica y la vigencia de un orden justo". Y el artículo 366 señala: "El bienestar general y el mejoramiento de la calidad de vida de la población son finalidades sociales del Estado...".

Consecuencia inmediata de tal cónfiguración será el prolijo y vasto desarrollo que de los «Derechos Sociales y Económicos" realiza la Constitución en su Capítulo 2, asi como de los que se denominan en su Capítulo 3 «De los Derechos Colectivos y del Ambiente", tal y como tendremos ocasión de examinar.

2. La Declaración de Derechos se proyecta e informa todo el nuevo ordenamiento jurídico politico que instaura el nuevo Texto constitucional de 1991. Proyección que ya apuntada, como hemos tenido ocasión de señalar, en el Preámbulo y en su artículo $1 .^{\circ}$, se explicita de forma particular en su articulo $5 .^{\circ}:$ «El Estado reconoce sin discriminación la primacia de los derechos inalienables de la persona y ampara a la familia como institución básica de la sociedad" 3 . Del mismo modo, y aunque de. una forma más concreta, inspirando el sentido y el ejercicio de las instituciones políticas, el artículo 188 de la Constitución, refiriéndose al Jefe del Estado, manifiesta: «... El Presidente de la República... se obliga a garantizar los derechos y libertades de todos los colombianos». De la misma manera, el artículo 95.4 impone a los particulares la obligación de «defender y difundir los derechos humanos».

3 El articulo 10.1 de la Constitución Española de 1978 señala: «La dignidad de la persona, los derechos inviolables que le son inherentes, el libre desarrollo de la personalidad, el respeto a la ley y a los derechos de los demás son fundamentos del orden politico y de la paz socialı. 
$Y$ es que, como se ha argumentado acertadamente, los derechos fundamentales «aspiran a tener validez como decisión constitucional jurídica básica para todos los campos del derecho" ${ }^{4}$.

3. Se trata de una Declaración completa y extensa, con una regulación bastante exhaustiva de los diversos derechos fundamentales y libertades públicas. Baste en este sentido con destacar lo que establece el artículo 94 del Texto constitucional: "La enunciación de los derechos y garantías contenidos en la Constitución y en los convenios internacionales vigentes, no debe entenderse como negación de otros que, siendo inherentes a la persona humana, no figuren expresamente en ellos».

Ordenación de los distintos derechos fundamentales que se recoge fundamentalmente en el Título II de la nueva Constitución. Título II que, denominado genéricamente «De los Derechos, las Garantias y los Deberes", se articula en cuatro capítulos: Capítulo 1 «De los Derechos Fundamentales»; Capitulo 2 «De los Derechos Sociales, Económicos y Culturales»; Capítulo 3 "De los Derechos Colectivos y del Ambiente", y el Capítulo 4 “De la Protección y Aplicación de los Derechos». Examinemos, pues, los mencionados capítulos.

I) Capitulo 1. «De los Derechos Fundamentales». En él la Constitución colombiana de 1991 ampara principalmente de un modo muy pormenorizado los diversos derechos fundamentales que, nacidos a la sombra del liberalismo político, definen la misma noción de Estado de Derecho, si bien se incluyen determinadas libertades que, al menos doctrinalmente, hubieran encontrado mejor reconocimiento en el Capítulo 2, cuando no parecen desbordar el contenido clásico de las Declaraciones de Derechos. La especial problemática de la estructura y de las relaciones socio-económicas actuales en Colombia se nos antoja la responsable de tan inacadémica regulación.

Pero retomando el alcance clásico de los derechos fundamentales tutelados en el presente capítulo, el Texto constitucional de 1991 reconoce expresamente los siguientes:

A) Derechos de ámbito personal. Entendiendo por éstos aquellos que se refieren a las cualidades y los atributos más elementales

4 Recogido en SCHNEIDER: “Peculiaridad y función de los derechos fundamentales en el Estado constitucional democrático", en Revista de Estudios Politicos, núm. 7, 1979 , p. 17. 
y preciados de la persona. Así, los artículos 11 y 12 amparan el derecho a la vida, la erradicación de la pena de muerte ${ }^{5}$ y de los atentados contra la integridad física de las personas: desaparición forzada, torturas y tratos o penas crueles, inhumanas o degradantes. El artículo 17 prohibe además «la esclavitud, la servidumbre y la trata de seres humanos en todas sus formas".

Se garantizan también las denominadas libertades de conciencia (art. 18) y de culto (art. 19), al mismo tiempo que se hace expresa declaración de la igualdad de todas las confesiones religiosas e iglesias. La primera, la libertad de conciencia, que supondria en un sentido amplio, «la posibilidad que el hombre tiene de elegir o elaborar por sí mismo las respuestas que dé a todas las cuestiones que le presente la conducta de su vida personal o social, así como la libertad de conformar a estas respuestas sus actividades y sus hábitos y de comunicar a los otros lo que tiene por cierto" 6 .

Por lo que respecta a la libertad religiosa, reconocida en el artículo 19, se pueden extraer dos conclusiones generales: en primer término, que la Constitución de 1991 instaura un Estado aconfesional; sin embargo, y en segundo lugar, no.por ello se trata de un Estado laico. Recordemos a este respecto el Preámbulo de la misma Constitución: «... delegatarios de la Asamblea Nacional, invocando la protección de Dios...", en un Estado donde además la gran mayoría de la población profesa la religión católica.

La Constitución colombiana de 1991 ampara, en segundo lugar, el derecho a la libertad y a la seguridad. Dice el artículo 28: "Toda persona es libre. Nadie puede ser molestado en su persona o familia, ni reducido a prisión o arresto, ni detenido... sino en virtud de mandamiento escrito de autoridad judicial competente, con las formalidades legales y por motivo propiamente definido en la ley». Derechos que, a los efectos de una mayor claridad expositiva, podemos desglosar en dos apartados. A saber: las garantias procesales propiamente dichas y los derechos del detenido.

En cuanto a las primeras, cabe mencionar las siguientes:

5 La Constitución Española de 1978 señala en su articulo 15: «... Queda abolida la pena de muerte, salvo lo que puedan disponer las leyes penales militares, para tiempos de guerra». La abolición que hace de la misma la Constitución Colombiana de 1991 en la línea de la Constitución Española, reforzaria «el carácter erga omnes del derecho a la vida que la Constitución reconoce a la persona, derecho que no pueden conculcar ni siquiera la sociedad o el Estado» (DE Esteban y Lopez GuerRa: Régimen Constitucional Español, vol. I, Madrid 1980, p. 143.

Rivero: Libertés Publiques, vol. I, Paris 1973, p. 120. 
- El principio de legalidad penal - «nullum crimen, nulla poena sine lege»-. "Nadie podrá ser juzgado sino conforme a las leyes sustanciales preexistentes al acto que se le imputa..." (art. 29) - correspondiéndole a la Fiscalía General de la Nación defender y vigilar dichas garantías (art. 250), incluso declarados los Estados de Excepción (art. 252).

- El principio general de irretroactividad de las leyes penales, por el que no se puede condenar por un acto que en el momento de cometerse no se halle tipificado como tal, ni imponerse una pena más grave que la prevista en el momento de la comisión del ilícito penal. Se reconoce, en cambio, la retroactividad de las leyes penales, cuando éstas son más favorables o menos restrictivas para el reo: «En materia penal la ley permisiva o favorable, aun cuando sea posterior, se aplicará de preferencia a la restrictiva o desfavorable” (art. 29).

- El principio de la presunción de inocencia, inicialmente formulado en el estricto ámbito del Derecho penal, y hoy elevado a la categoría de principio constitucional en los Textos constitucionales modernos: "Toda persona se presume inocente mientras no se haya declarado judicialmente culpable» (art. 29).

- Y en fin, uel derecho de toda persona a acceder libremente a la administración de justicias (art. 229), el reconocimiento del derecho al Juez ordinario - «... ante juez o tribunal competente» (art. 29) - el derecho, como principio general, a la apelación o consulta de toda sentencia judicial - «Toda sentencia judicial podrá ser apelada o consultada, salvo las excepciones que consagra la ley (art. 31)-, y el derecho al debido proceso sin dilaciones injustificadas" (art. 29). Asimismo se establece la nulidad de toda prueba obtenida ilicitamente (art. 29), y la prohibición para los tribunales de justicia superiores de agravar las penas cuando los condenados sean apelantes únicos (art. 31).

Por lo que respecta a los que denominamos derechos del detenido, y como principio general, se prohibe tanto la prisión, el arresto o la detención, "sino con mandamiento escrito de autoridad judicial competente, con las formalidades legales y por motivo previamente definido en la ley, salvo flagrante delito"s (art. 32), como «la detención, prisión, arresto por deudas o medida de seguridad imprescriptibles" (art. 28). Se garantizan final- 
mente los derechos de asistencia al detenido. "Quien sea sindicado tiene derecho a la defensa y a la asistencia de un abogado escogido por él, o de oficio, durante la investigación y el juzgamiento" (art. 29).

En la misma línea se admite la posibilidad de plantear la legalidad de la detención a través del procedimiento de habeas corpus, que encontrando su origen en Inglaterra en el llamado Habeas Corpus Amendment Act de 1679, ha sido recogido genéricamente en la mayoría de los Textos constitucionales modernos. Habeas corpus que, dice el artículo 30 , habrá de resolverse en el plazo máximo de treinta y seis horas. Idéntico periodo de tiempo se fija en el artículo 28 como plazo máximo para la detención del individuo antes de su puesta en libertad o a disposición de la autoridad judicial competente.

Finalmente se introducen en el Texto constitucional determinados principios de orden procesal y penal sustantivo, como la prohibición de declarar contra uno mismo o contra su cónyuge (art. 33), la prohibición de las penas de destierro, confiscación y prisión perpetua (art. 34), así como la específica de extradición para los colombianos de nacimiento, y la declaración de la justicia colómbiana como única jurisdicción competente para conocer de aquellos delitos que, cometidos por colombianos en el exterior, sean asimismo considerados como tales por la legislación nacional (art. 35). Ambos supuestos fuertemente vinculados en la práctica a los delitos de narcotráfico.

B) Derechos de la esfera privada. Intimamente relacionados con los derechos de ámbito privado, y que recaen asimismo sobre cualidades esencialisimas de la persona humana. Ambas categorias, derechos de la esfera privada y derechos de ámbito privado, configurarían lo que en el constitucionalismo inglés se denomina con la expresión "freedom from», y que JELLINEK, en su construcción de los derechos públicos subjetivos, Ilamó «status libertatis».

Dentro de estos derechos de la esfera privada destacaria, en primer término, el estricto derecho a la vida privada, «el derecho a que le dejen a uno tranquilo" 7 , cuyas principales manifestaciones serian el derecho a la honra, a la intimidad y al buen nombre. Dice el artículo 15: «Todas las personas tienen derecho a la intimidad personal y familiar, y a su buen nombre.

7 Carbonnier: Droit Civil, tomo I, Paris 1965, p. 239, citado por Robert: Libertés Publiques, Paris 1971, p. 245. 
y el Estado debe respetarlos y hacerlos respetar". $Y$ el articulo 21 manifiesta: "Se garantiza el derecho a la honra. La ley señalará la forma de su protección».

Protección de la vida privada que adquiere caracteres hasta ahora desconocidos con el destacado desarrollo de la tecnologia y la informática en los tiempos actuales. En este sentido, y de igual manera que el artículo 35 de la Constitución portuguesa de $1976^{8}$ y el artículo 18.3 de la Constitución española de $1978^{9}$, el Texto constitucional colombiano de 1991 procura evitar la llamada «dictadura de los expedientes»: «De igual modo (los ciudadanos) tienen derecho a conocer, actualizar y rectificar las informaciones que se hayan recogido sobre ellos en bancos de datos y en archivos de entidades públicas y privadas. En la recolección, tratamiento y circulación de datos se respetará siempre la libertad y demás garantias consagradas en la Constitución» ${ }^{10}$.

En segundo término, se reconoce tanto la inviolabilidad de domicilio, como las libertades de circulación, permanencia, residencia, entrada y salida del pais. Y es que, como señalaba RUIZ DEL CASTILLO "si la 'inviolabilidad' del domicilio constituye garantia de que el hombre es libre en su casa, la 'libertad' de domicilio constituye garantía de que la casa es libre en la ciudad» ${ }^{11}$.

Respecto del primero, el artículo 28 señala: «Nadie puede ser molestado... ni su domicilio registrado, sino en virtud de mandamiento escrito de autoridad judicial competente, con las formalidades legales y por motivo previamente definido en la ley». Excepción, mediante resolución judicial previa, a la que ha de añadirse el supuesto de flagrante delito: «El delincuente sorprendido en flagrancia podrá ser aprehendido y llevado ante el juez por cualquier persona. Si los agentes de la autoridad lo per-

- El artículo 35 de la Constitución Portuguesa dice: "1. Todos los ciudadanos tendrán derecho a tomar conocimiento de lo que conste en forma de registros mecanográficos acerca de ellos y de la finalidad a que se destinan las informaciones, y podrán exigir la rectificación de los datos, asi como su actualización.

2. No se podrá utilizar la informática para el tratamiento de datos referentes a convicciones políticas, fe religiosa o vida privada, salvo cuando se trate de la elaboración de datos no identificables para fines estadísticos.

3. Se prohibe atribuir un número nacional único a los ciudadanos.»

9 La Constitución Española de 1978 en su artículo 18.4 señala: "La ley limitará el uso de la informática para garantizar el honor y la intimidad personal y familiar de los ciudadanos y el pleno ejercicio de sus derechos".

10 MILLER: “The Assault on Privacy: Computers, Data Banks and Dossiers", recogido en Duchacek: Derechos y libertades en el mundo actual, trad. esp., Madrid 1976, p. 108.

11 Ruiz del Castillo: Derecho Politico, Madrid 1934, p. 208. 
siguiesen y se refugiase en su propio domicilio, podrán penetrar en él, para el acto de la aprehensión; y si se acogiera a domicilio ajeno deberá proceder requerimiento del morador» (art. 32).

En cuanto a las libertades de circulación, permanencia, residencia, entrada y salida del pais, lo que la doctrina francesa denomina «la liberté d'aller et venir», y la italiana "diritto de expatrio, locomozione e soggiorno", el artículo 24 del Texto constitucional manifiesta: "Todo colombiano, con las limitaciones que establece la ley, tiene derecho a circular libremente por el territorio nacional, a entrar y salir de él, y a permanecer y residenciarse en Colombia». Hagamos dos reflexiones, no obstante, sobre el ámbito de las mencionadas libertades.

En primer término, y en cuanto a su ámbito subjetivo, es decir, los sujetos del derecho, la Constitución de 1991 se ha decantado por una tutela restringida referida en principio a sus propios nacionales — «Todo colombiano...»-, donde parecen haber influido fundamentalmente razones de seguridad públi$\mathrm{ca}^{12}$. Libertades de circulación y residencia sometidas, en cualquier caso, a diferentes limitaciones, tanto de carácter general (detenciones, arrestos etc.), como más particulares. Entre estas últimas, y refiriéndose al Departamento Archipiélago de San Andrés, Providencia y Santa Calina, el artículo 310 de la Constitución señala: "Mediante una ley aprobada por la mayoría de los miembros de cada Cámara se podrá limitar el ejercicio de los derechos de circulación y residencia, establecer controles a la densidad de la población, regular el uso del suelo y someter a bienes inmuebles con el fin de proteger la identidad cultural de las comunidades nativas y preservar el medio ambiente y los recursos naturales del Archipiélago".

En segundo lugar, y por lo que se refiere a la extensión y al contenido de las mentadas libertades de entrada y salida, las únicas excepciones de carácter general, que en la línea de otras legislaciones comparadas podrian oponerse legalmente a la denegación de los correspondientes pasaportes, serian básicamente las siguientes: la existencia de obligaciones de naturaleza militar, la necesidad de asegurar el curso de las acciones penales o la ejecución de medidas de seguridad preventiva, o en fin, el

12 El artículo 19 de la Constitución Española de 1978 establece: «Los españoles tienen derecho a elegir libremente su residencia y circular por el territorio nacional. Asimismo, tienen derecho a entrar y salir libremente de España en los términos que la ley establece. Este derecho no podrá ser limitado por motivos políticos o ideológicos". 
supuesto de los menores de edad sometidos a la tutela y patria potestad $^{13}$.

De la misma naturaleza es el reconocimiento del secreto de las comunicaciones: "La correspondencia y demás formas de comunicación privada son inviolables" (art. 15). Y es que, la «libertad privada exige que la carta, a la vez reflejo - por las noticias que contiene- $\mathrm{e}$ instrumento - por los proyectos que prepara - de la vida privada, no sea conocida sino por aquel a quien va destinadas ${ }^{14}$.

Derecho el secreto de las comunicaciones que reviste, en todo caso, dos aspectos: el derecho de no obstaculizar tanto su envio como su recepción, asi como la garantía de su secreto ${ }^{15}$. De acertada hay que calificar asimismo la redacción del constituyente que no se limitó a asegurar la protección específica de la correspondencia, sino de todas las «demás formas de comunicación privada» ${ }^{16}$.

Finalmente, y también dentro de estos derechos de la esfera privada, se hallaría el derecho al matrimonio - «Por la decisión libre de un hombre y una mujer de contraer matrimonio..." (art. 42)-, con una especial protección de la familia y de los hijos. Derecho al matrimonio que se regula de acuerdo con las siguientes coordenadas: en primer lugar, la igualdad juridica del hombre y de la mujer (arts. 42 y 43), ya enunciada genéricamente también en el artículo 13; en segundo término, la remisión del constituyente a la legalidad ordinaria en los detalles relativos a las formas de matrimonio, edad, capacidad, derechos y deberes (art. 42), atribuyendo efectos civiles al matrimonio religioso (art. 42); finalmente, y en una línea coherente con las citadas libertades de pensamiento y religión, el reconocimiento de los supuestos de separación y disolución (art. 42).

C) Derechos de ámbito político. Derechos que JELLINEK denominaba «status activae civitatis», y que se instrumentan en el Estado de Derecho como complementarios del «status libertatis»

13 Sobre el tema en general ver, Gonzalez Trevijano: Libertades de circulación, residencia, entrada y salida de España, Madrid 1991.

14 RIVERO; op. cit., p. 71. 1963, p. 163.

15 ItALIA: Liberta a segretezza della corrispondenza e della comunicazione, Milán que establezca la ley. Para efectos tributarios, judiciales y para los casos de imposición, vigilancia e intervención del Estado, podrá exigirse la presentación de libros de contabilidad y demás documentos privados en los términos que señala la ley". 
examinado. De entre ellos destacariamos en primer lugar la libertad de expresión que, enunciada ya en el artículo 11 de la Declaración Francesa de Derechos del Hombre y del Ciudadano de 1789 - «libre.comunicación de los pensamientos y las opiniones»-, se presenta como una de las piedras angulares en que descansa todo Estado Democrático de Derecho ${ }^{17}$.

Libertad de expresión que podriamos definir, en un sentido amplio, "como el derecho a recibir información objetiva y veraz, a expresar libremente las propias ideas y opiniones y a tener acceso para ello, individualmente o como grupo, a los medios que posibiliten la efectiva difusión de tales ideas y opiniones" ${ }^{18}$. Asi comprendida la libertad de expresión se nos antoja, tanto como una específica manifestación de la libertad personal, cuanto garantía institucional de la misma sociedad.

Veamos, pues, sus manifestaciones más principales que recoge expresamente la Constitución de 1991:

- El artículo 20 ampara el derecho a la libertad de expresión de una forma amplia y genérica: «Se garantiza a toda persona la libertad de expresar y difundir sus pensamientos y opiniones...".

Del mismo modo se establece la libertad de sfundar medios masivos de comunicación", que entendemos hay que poner en relación con lo que también señala el artículo 77: "La dirección de la politica que en materia de televisión determine la ley sin menoscabo de las libertades consagradas en esta Constitución...". Medios masivos de comunicación libres, responsables, y en los que se garantiza el derecho de rectificación en condiciones de equidad. Asimismo, se define su carácter de bien público, y se asegura la igualdad de oportunidades en el campo del espectro electromagnético (arts. 75 y 76).

- La libertad de cátedra, como expresión inmediata e ineludible del pluralismo político e ideológico, tutelada constitucionalmente en el artículo 27: «El Estado garantiza las libertades de enseñanza, aprendizaje, investigación y cátedra». Libertad de cátedra necesitada de una especial protección en la convulsionada convivencia sociopolítica colombiana,

17 «... los ciudadanos no pueden tener una auténtica participación politica, no pueden informar, criticar, controlar ni deponer a los gobernantes a no ser que sean libres para exponer puntos de vista diferentes", DUCHACEK: op. cit., p. 289.

18 Esteban y López Guerra: op. cit., p. 165. 
y entendida como «la exención de trabas que ha de tener todo profesor para investigar, expresar y transmitir el saber científico" ${ }^{19}$.

- El reconocimiento constitucional de los derechos a la información y de los derechos del informador: «Se garantiza a toda persona la libertad... de informar y recibir información veraz e imparcial» (art. 20). Como se ha señalado acertadamente, wen nuestro siglo, la piedra de toque para clasificar un régimen político consiste en el modo que se ejerza y respete el derecho a la información» ${ }^{20}$. En este contexto, la protección de la actividad periodística, el acceso libre a los documentos públicos - habrá que concretar el ámbito y la extensión de los «secretos oficiales"-, la naturaleza inviolable del secreto profesional, y la prohibición de la censura (arts. 73 y 74) se presentan como desarrollo y complemento necesario de las libertades.

En segundo lugar, y dentro de los denominados derechos de ámbito político, se destaca la libertad de reunión. Libertad de reunión, que comprendida como «el derecho a agruparse con otras personas por un tiempo y un fin determinado y con un mínimo de organización, en lugar abierto o cerrado, para intercambiar ideas $u$ opiniones y para defender intereses comunes» ${ }^{21}$, se halla amparada en el artículo 37: «Toda parte del pueblo puede reunirse y manifestarse pública y pacíficamente. Sólo la ley podrá establecer de manera expresa los casos en los cuales se podrá limitar el ejercicio de este derecho". Respecto de ella, y aunque en el precepto constitucional señalado no se menciona, hay que entender en el posterior desarrollo legislativo, como reuniones prohibidas, aquellas reuniones no pacíficas o en las que se portan armas de un modo indiscriminado ${ }^{22}$. Asimismo el artículo 37 reconoce el derecho de manifestación, si bien de un modo muy genérico e indeterminado ${ }^{23}$. 1977, p. 82.

19 Lucas Verdú: Curso de Derecho Político, tomo III, Madrid 1976, p. 173.

20 Sauvy: Le pouvoir et l'opinion, Paris 1949, p. 37.

21 PECES-BARBA: Sobre las libertades públicas en el Estado Español, Valencia

${ }_{22}$ Si lo hace, en cambio, el artículo 21 de la Constitución Española de 1978: «Se reconoce el derecho de reunión pacífica y sin armas. El ejercicio de este derecho no necesitará autorización previa». Tampoco se señala, pues, nada respecto de su régimen legal: la necesidad de autorización previa administrativa, la mera obligación de comunicación a la Administración, o en fin, un régimen de absoluta libertad al respecto. Ver recientemente, TORRES MURO: El derecho de reunión y manifestación, Madrid 1991.

${ }^{23}$ Por contra, y a título de ejemplo, el citado artículo 21 de la Constitución Española de 1978 manifiesta: EEn los casos de reuniones en lugares de tránsito público y 
En tercer término, se tutela expresamente el derecho de asociación. Libertad de asociación, en cuanto «institución de un concurso de voluntades que consiste en una agrupación, con vocación de permanencia, de una pluralidad de personas para la realización de unos fines sin ánimo de lucro" ${ }^{24}$, que encuentra su amparo constitucional en el artículo 38: "Se garantiza el derecho de libre asociación para el desarrollo de las distintas actividades que las personas realizan en sociedad» ${ }^{25}$.

Dentro de ella hay que resaltar «el derecho a fundar, organizar y desarrollar partidos y movimientos políticos, y la libertad de afiliarse o retirarse de ellos", que recoge el artículo 107 del Texto constitucional colombiano, y sobre el que volveremos, no obstante, en particular más adelante.

En cuarto lugar, el Derecho de Petición, con origen en la Petition of Rights (1628) y en el articulo $5 .^{\circ}$ del posterior Bill of Rights (1688) - «es un derecho de los súbditos presentar peticiones al Rey, siendo ilegales las prisiones y procesamientos de los peticionarios»-, encuentra también su tutela en el artículo 23 de la Constitución de 1991. Dice el artículo 23: «Toda persona tiene derecho a presentar peticiones respetuosas a las autoridades por motivo de interés general o particular, y a obtener pronta resolución. El legisador podrá reglamentar el ejercicio de este derecho ante organizaciones privadas para garantizar los derechos fundamentales» ${ }^{26}$.

manifestaciones se dará comunicación previa a la autoridad, que sólo podrá prohibirlas cuando existan razones fundadas de alteración del orden público para personas o bienes». Ver también el artículo 107 de la Constitución Colombiana.

24 Peces-Barba: op. cit., p. 101.

25 Así, y por ejemplo, el artículo 22 de la Constitución Española de 1978 especifica la legalidad de sus fines, la actividad de los órganos judiciales en los supuestos de disolución y supresión, o la prohibición de determinadas asociaciones, como las secretas o de carácter paramilitar.

Dice el artículo 22 de la Constitución Española: “1. Se reconoce el derecho de asociación.

2. Las asociaciones que persigan fines o utilicen medios tipificados como delito son ilegales.

3. Las asociaciones constituidas al amparo de este artículo deberán inscribirse en un registro a los solos efectos de publicidad.

4. Las asociaciones sólo podrán ser disueltas o suspendidas en sus actividades en virtud de resolución judicial motivada.

5. Se prohiben las asociaciones secretas y las de carácter paramilitar».

Ver en este sentido también el artículo 39 de la Constitución Colombiana de 1991 y el artículo 219 con respecto a la Fuerza Pública.

${ }_{26}$ El artículo 29 de la Constitución Española de 1978 señala: «1. Todos los españoles tendrán el derecho de petición individual o colectiva, por escrito, en la forma y con los efectos que determine la ley.

2. Los miembros de las Fuerzas o Institutos armados o de los Cuerpos sometidos a disciplina militar podrán ejercer este derecho sólo individualmente y con arreglo a lo dispuesto en su legislación específica». 
Derechos de ámbito político en los que habría que incluir, finalmente, las manifestaciones recogidas en el artículo 40 y en el Título IV de la Constitución:

1. Elegir y ser elegido.

2. Tomar parte en elecciones, plebiscitos, referendos, consultas populares y otras formas de participación democrática.

3. Constituir partidos, movimientos y agrupaciones políticas sin limitación alguna; formar parte de ellos libremente y difundir sus ideas y programas.

4. Revocar el mandato de los elegidos en los casos y en la forma que establecen la Constitución y la ley.

5. Tener iniciativa en las corporaciones públicas.

6. Interponer acciones públicas en defensa de la Constitución y de la ley.

7. Acceder al desempeño de funciones y cargos públicos, salvo los colombianos, por nacimiento o por adopción, que tengan doble nacionalidad. La ley reglamentará esta excepción y determinará los casos a los cuales ha de aplicarse.

Las autoridades garantizarán la adecuada y efectiva participación de la mujer en los niveles decisorios de la Administración Pública».

Dependiendo todos ellos, en cualquier caso, del previo disfrute de la ciudadanía colombiana. A este respecto el artículo 99 señala: "La calidad de ciudadano en ejercicio es condición previa indispensable para ejercer el derecho de sufragio, para ser elegido y para desempeñar cargos públicos que llevan anexa autoridad o jurisdicción». Y el artículo 101 manifiesta: "Los derechos políticos se reservan a los nacionales, pero la ley podrá conceder a los extranjeros residentes en Colombia el derecho al voto en las elecciones y consultas populares de carácter municipal o distrital». Voto, que de acuerdo con el artículo 258 se configura no sólo como derecho, sino también como deber, restringido, sin embargo, a los miembros de la fuerza pública en activo (art. 219).

D) Derechos de ámbito socio-económico. En primer término, y en cuanto a la libertad de sindicación, expresamente reconocida 
en el artículo 39, puede ser objeto de la siguiente exégesis: se atribuye tanto a trabajadores como empresarios; el acta de constitución es suficiente para obtener su reconocimiento juridico; la preceptiva acomodación de sus estructuras y funcionamiento al orden legal y a los principios democráticos, de acuerdo con lo apuntado en el Preámbulo y en el artículo $1 .^{\circ} \mathrm{del}$ propio Texto constitucional; $y$, en fin, la exclusiva intervención de los órganos judiciales en los supuestos de cancelación y suspensión.

También se garantiza el derecho al trabajo, que podemos desglosar principalmente en tres manifestaciones: en primer lugar, y aunque el artículo 25 lo califica no sólo de derecho, sino también de obligación social, se podria quizá defender una teórica libertad negativa de trabajar; en segundo término, la libertad material de trabajar cuando asi se desee; en tercer lugar, la libertad de elección de profesión u oficio (art. 36), reconociéndose finalmente el derecho de todo profesional para organizarse en colegiaturas. Regulación constitucional que hay que completar, necesariamente, con el aseguramiento de que el trabajo se realice en «condiciones dignas y justas», así como la extrapolación del principio y derecho constitucional de la no discriminación por razón de sexo que amparan los artículos 13 y 43: «Toda persona goza... de los mismos derechos, libertades y oportunidades sin ninguna discriminación por razones de sexo...».

Se echa en falta, por el contrario, en el presente Capitulo 1 "Derechos Fundamentales», así como en el Capítulo 2 «Derechos Sociales y Económicos», una referencia expresa a la libertảd de empresa, que no se trata hasta el Título XII, «Del Régimen económico y Hacienda Pública»: «La empresa, como base del desarrollo, tiene una función social que implica obligaciones. El Estado fortalecerá las organizaciones solidarias y estimulará el desarrollo empresarialı (art. 333).

En cambio, y dentro de lo que se ha denominado la Constitución económica -las normas básicas destinadas a proporcionar el marco juridico fundamental para la estructura y el funcionamiento de la actividad económica, o dicho de otro modo, para el orden y el proceso económico-, se afirman expresamente los siguientes principios: en primer término, la declaración de que «la actividad económica y la iniciativa privada, son libres dentro de los límites del bien común»; en segundo lugar, el reconocimiento de «la libre competencia como un derecho de todos"; en tercer término, la atribución al Estado de la dirección general de la economía (art. 334); finalmente, el establecimiento de un «Plan Nacional de Desarrollo conformado por una parte General y un Plan de Inversiones de las entidades públicas del 
orden nacional’' (art. 339), asi como la creación a estos efectos de un Consejo Nacional de Planeación y de Consejos Territoriales de Planeación (art. 340).

El derecho de huelga y el derecho de propiedad se recogen, en cambio, en el Capítulo 2 "De los Derechos Sociales y Económicos". Asimismo, y a caballo entre estos derechos de ámbito socio-económico y los derechos de ámbito personal, se encuentra la libertad de enseñanza. Libertad de enseñanza que amparada en el artículo 27, junto con las libertades de investigación y cátedra, se regula más pormenorizadamente también en el Capítulo 2, al que nos remitimos pues para el examen de ambas.

El presente Capítulo 1 - Derechos Fundamentales»- se completa además con el reconocimiento general del principio de igualdad ante la ley que se recoge en el artículo 13: «Toda persona nace libre e igual ante la ley y recibirá la misma protección y trato de las autoridades, y gozarán de los mismos derechos, libertades y oportunidades, sin ninguna discriminación por razones de sexo, raza, origen nacional o familiar, lengua, religión, opinión política o filosófica". A este respecto, el Estado habrá de promover «las condiciones para que la igualdad sea real y efectiva», brindando una especial protección a aquellas personas y grupos objeto de discriminación, marginación, o en situaciones de debilidad manifiesta ${ }^{27}$. Y es que, dice el artículo 14, «toda persona tiene derecho al reconocimiento de su personalidad jurídica", protegiéndose expresamente además la diversidad étnica y cultural (art. $7 .{ }^{\circ}$ ).

Se trata, pues, del entendimiento del principio de igualdad en el sentido ya apuntado en el artículo $3 .^{\circ}$ de la Constitución Italiana de $1947^{28}$, que no conformándose con un alcance meramente formal, en la línea de los revolucionarios liberales del siglo xvill, sino también sustancial, permite la adopción de medidas diferentes, que no discriminatorias, a situaciones objetivamente distintas.

${ }^{27}$ El artículo 9.2 de la Constitución Española manifiesta: "Corresponde a los poderes públicos promover las condiciones para que la libertad y la igualdad del individuo y de los grupos en que se integra sean reales y efectivas; remover los obstáculos que impidan o dificulten su plenitud y facilitar la participación de todos los ciudadanos en la vida política, económica, cultural y social».

${ }_{28}$ El artículo $3^{\circ}$ de la Constitución Italiana de 27 de diciembre de 1947 establece: "Todos los ciudadanos tienen igualdad de derechos sociales y son iguales ante la ley, sin distinción de sexo, de raza, de lengua, de religión, de opiniones políticas y de condiciones personales y sociales.

Es misión de la República remover los obstáculos de orden económico y social que, limitando de hecho la libertad y la igualdad de los ciudadanos, impiden el pleno desenvolvimiento de la personalidad humana y la efectiva participación de todos los trabajadores en la organización política y social del país". 
Juicio favorable reviste asimismo la inclusión de un derecho genérico «al libre desarrollo de la personalidad» (art. 16), y la defensa expresa de la paz como un "derecho y deber de obligatorio cumplimiento" (art. 21).

Finalmente, y por lo que atañe a la condición y situación de los extranjeros, el artículo 36 recoge el derecho de asilo: "Se reconoce el derecho de asilo en los términos previstos en la ley" ${ }^{29}$.

II) Capitulo 2 "De los Derechos Sociales y Económicos" y Capitu103 «De los Derechos Colectivos y del Ambiente». La configuración del Estado colombiano como un Estado Social de Derecho (art. 1. ${ }^{\circ}$ ), supone, como apuntamos, la superación de los clásicos principios liberales de naturaleza abstencionista ${ }^{30}$ que reducian el papel del Estado al ejercicio de las funciones de defensa, policía y servicios más esenciales y básicos, para pasar a desarrollar un papel inmediato, directo y activo en las relaciones sociales y económicas, promoviendo «la prosperidad general y garantizando la efectividad de los principios, derechos y deberes consagrados en la Constitución» (art. 2. ${ }^{\circ}$ ).

Manifestaciones de este Estado Social de Derecho son, en este sentido, el reconocimiento y la protección de los siguientes derechos, que podemos agrupar atendiendo a las siguientes categorias:

\section{A) Derechos de la familia y de la infancia que, enunciados ya en}

${ }^{29}$ El artículo 100 de la Constitución Colombiana señala: «Los extranjeros disfrutarán en Colombia de los mismos derechos civiles que se conceden a los colombianos. No obstante, la ley podrá, por razones de orden público, subordinar a condiciones especiales o negar el ejercicio de determinados derechos civiles a los extranjeros.

Asimismo, los extranjeros gozarán, en el territorio de la República, de las garantías concedidas a los nacionales, salvo las limitaciones que establezca la Constitución o la ley.

Los derechos politicos se reservan a los nacionales pero la ley podrá conceder a los extranjeros residentes en Colombia el derecho al voto en las elecciones y consultas populares de carácter municipal o distrital».

A título de ejemplo, el artículo 13 de la Constitución Española de 1978 dice: «1. Los extranjeros gozarán en España de las libertades públicas que garantiza el presente Título en los términos que establezcan los tratados y la ley.

2. Solamente los españoles serán titulares de los derechos reconocidos en el artículo 23, salvo lo que, atendiendo a criterios de reciprocidad, pueda establecerse por tratado o ley para el derecho de sufragio activo en las elecciones municipales.

3. La extradición sólo se concederá en cumplimiento de un tratado o de la ley, atendiendo al principio de reciprocidad. Quedan excluidos de la extradición los delitos políticos, no considerándose como tales los actos de terrorismo.

4. La ley establecerá los términos en que los ciudadanos de otros paises y los apátridas podrán gozar del derecho de asilo en España».

${ }_{30}$ En este sentido, por ejemplo, el artículo 20.1 de la Ley Fundamental de Bonn de 23 de mayo de 1949: "La República Federal de Alemania es un Estado Federal, democrático y social.» El artículo 1. ${ }^{\circ}$ de la Constitución Italiana de 27 de diciembre de 1947, siguiendo la línea inspiradora del artículo $10^{\circ}$ de la Constitución Española de la II República de 1931 - «España es una República de trabajadores»-, señala: «Italia es una república democrática basada en el trabajo». 
el artículo $5 .^{\circ}$, se refuerzan en los artículos 42 y 44 . En estos términos de especial protección se señalará: «Los derechos del niño prevalecen sobre los derechos de los demás» (art. 44), en la linea de la Declaración Universal de los Derechos del Niño de 20 de noviembre de 1959.

B) Especial atención asimismo a determinados sectores de la población: la adolescencia, la tercera edad y los disminuidos físicos y mentales. En cuanto a los adolescentes el artículo 45 establece: «El adolescente tiene derecho a la protección y a su formación integral. El Estado y la sociedad garantizan la participación activa de los jóvenes en los organismos públicos y privados que tengan a cargo la protección, educación y progreso de la juventud». Por lo que se refiere a la tercera edad, el artículo 47 manifiesta: «El Estado, la sociedad y la familia concurrirán para la protección y la asistencia de las personas de la tercera edad y promoverán su integración en la vida activa y comunitaria...». Finalmente, y por lo que atañe a los disminuidos, el artículo 47 señala: «El Estado alentará una política de previsión, rehabilitación e integración social para los disminuidos físicos, sensoriales y psíquicos...». Normativa que hay que completar con la especial atención a los minusválidos en materia laboral (art. 54) ${ }^{31}$.

C) Derechos de los trabajadores. El derecho al trabajo amparado, como tuvimos ocasión de ver, en el artículo 25 - «El trabajo es un derecho de las personas y una obligación social..."-, se reafirma en el artículo 53 del Capitulo 2 «Derechos Sociales y Económicos", con el establecimiento de los siguientes criterios y medidas:

«- La obligación del Congreso Nacional de aprobar el Estatuto del Trabajo, en el que se atenderán los siguientes principios fundamentales: «Igualdad de oportunidades para los trabajadores; remuneración mínima vital y móvil, proporcional a la cantidad y calidad de trabajo; estabilidad en el empleo; irrenunciabilidad a los beneficios mínimos establecidos en normas laborales; facultades para transigir y conciliar sobre derechos inciertos y discutibles; situación más favorable al trabajador en caso de duda en la aplicación e interpretación de las fuentes formales de derecho; primacía de la realidad sobre formali-

31 Derechos reconocidos prolijamente en los artículos 70,71 y 72 de la Constitución Portuguesa de 1976, y 49 y 50 de la Constitución Española de 1978. 
dades establecidas por los sujetos de las relaciones laborales; garantía a la segurìdad social, la capacitación, el adiestramiento y el descanso necesario; protección especial a la mujer, y a la maternidad y al trabajador menor de edad.

El Estado garantiza el derecho al pago oportuno y al reajuste periódico de las pensiones legales. Los convenios internacionales del trabajo debidamente ratificados hacen parte de la legislación interna.

La ley, los contratos, los acuerdos y convenios de trabajo, no pueden menoscabar la libertad, la dignidad humana ni los derechos de los trabajadores".

- El reconocimiento de los derechos de uformación y rehabilitación profesional y técnica a quienes lo requieran» (art. 54).

- La consideración de la Seguridad Social como un «servicio público, de carácter ubligatorio que se presta bajo la dirección, coordinación y control del Estado, en sujeción a los principios de eficacia, universalidad y solidaridad en los términos que establece la ley...", y que se articula a través de entidades tanto públicas como privadas.

- Sin embargo, y de entre todos ellos, los derechos más sobresalientes serían el derecho a la negociación colectiva, las medidas de conflicto colectivo (art. 55), y por su especial importancia el derecho de huelga (art. 56). Dice el artículo 56: «Se garantiza el derecho de huelga, salvo en los servicios públicos esenciales definidos por el legislador. La ley reglamentará este derecho...".

Regulación constitucional que puede ser objeto, en todo caso, de las siguientes reflexiones: en primer término, entendemos que el presente derecho de huelga habria de haberse incluido quizás mejor en el Capitulo 1 "Derechos Fundamentales", junto con el derecho de sindicación (art. 39); en segundo lugar, y en cuanto a su ámbito subjetivo, nos parece en cambio muy acertado un reconocimiento tan genérico y amplio; en tercer término, se nos antoja también ade- 
cuada la creación de una Comisión permanente «integrada por el Gobierno, representantes de los empleadores y de los trabajadores, para fomentar las buenas relaciones laborales, contribuir a la solución de los conflictos colectivos de trabajo y concentrar las políticas salariales y laborales».

- Finalmente, se prevé el «establecimiento de los estímulos y medios para que los trabajadores participen en la gestión de las empresas» (art. 57).

D) El derecho de propiedad privada, una de las piedras angulares en que descansaba el liberalismo de los siglos XVIII y XIX, se encuentra sin embargo sometido en la actualidad a importantes límites y condicionamientos, alejándose mucho del carácter absoluto, personalista y casi sagrado de otros tiempos. Así el artículo 58, si bien garantiza «la propiedad privada y los demás derechos adquiridos con arreglo a las leyes civiles», también preceptúa su función social y la subordinación del interés privado al interés público, destacándose la mención de su función ecológica.

Función social de la propiedad que se expresa con toda claridad con la previsión constitucional, como criterio general, de la expropiación, si bien mediante sentencia judicial e indemnización previa ${ }^{32}$, que se «fijará consultando los intereses de la comunidad y del afectado". No obstante, y por «razones de equidad", podrá procederse excepcionalmente a su expropiación sin el pago de la correspondiente indemnización. Medida que, no siendo controvertible judicialmente, requerirá sin embargo el voto favorable de la mayoría absoluta del Senado y de la Cámara de los Representantes. Asimismo, y en caso de guerra, "la necesidad de una expropiación podrá ser decretada por el Gobierno Nacional sin previa indemnización», si bien en tales supuestos la propiedad del inmueble sólo podrá ser ocupada temporalmente, ya sea "para atender a las necesidades de la guerra, ya para destinar a ella sus productos» (art. 52). De igual suerte, aunque el artículo 34 prohibe su confiscación, si prevé en cambio, mediante sentencia judicial, la extinción del «dominio sobre los bienes adquiridos mediante enriquecimiento ilicito". social, mediante la correspondiente indemnización y de conformidad con lo dispuesto en las leyes". 
Finalmente, se señala la función promocional del Estado con respecto al acceso a la propiedad (art. 60), sobre todo en lo que atañe a los trabajadores agrícolas (art. 64), y a sus formas asociativas y solidarias (art. 60).

En cuanto a las donaciones intervivos y testamentarias el articulo 62 garantiza que su destino «no podrá ser variado ni modificado por el legislador, a menos que el objeto de la donación desaparezca". Se tutela, además específicamente, el derecho de propiedad intelectual (art. 61).

E) Derecho a la salud, y a los demás bienes y derechos de semejante naturaleza. Así, y con carácter general, se establece la atención a la salud y el saneamiento ambiental tanto como un derecho (art. 79), como cuanto un servicio público a cargo del Estado (art. 49). De idéntico modo se afirma el control de calidad de los bienes y servicios ofrecidos y prestados a la comunidad, garantizándose la participación de las organizaciones de consumidores y usuarios (art. 78). En la misma línea el artículo 65 adjudica a la producción de alimentos una especial protección del Estado, con especial relevancia en el ámbito agropecuario.

En cuanto a la preservación del medio ambiente ${ }^{33}$, disfrutan de competencias al respecto, tanto los departamentos y municipios generales (arts. 289, 300.3 y 313.9), como los de los territorios indígenas (arts. 330 y 331), atribuyéndose asimismo al Controlador General de la República la presentación ante el Congreso de un informe anual sobre el estado de los recursos naturales y del medio ambiente (art. 268.7).

Plausible nos parece, y así debe destacarse, la prohibición de la ufabricación, importación, posesión y uso de armas químicas, biológicas y nucleares, así como la introducción al territorio nacional de residuos nucleares y desechos tóxicos" (art. 81).

Finalmente se recoge también el derecho «a la recreación, a la práctica del deporte y al aprovechamiento del tiempo libre» (art. 52), exigiéndose, en todo caso, la estructura democrática de las organizaciones deportivas ${ }^{34}$.

${ }^{33}$ De este modo la Constitución Colombiana de 1991 continúa la línea iniciada por la Constitución Portuguesa de 1976 (arts. 64 y 66) y por la Constitución Española de 1978 (arts. 43 y 45), reconociendo los derechos constitucionales a la salud y al medio ambiente.

${ }^{34}$ En el mismo sentido se manifiestan la Constitución Portuguesa de 1976 (art. 79) y la Constitución Española de 1978 (art. 43.3). 
F) Derecho a la vivienda. Derecho a la vivienda que, reconocido en el artículo 50 - «Todos los colombianos tienen derecho a una vivienda digna...»-, se complementa con la declaración constitucional de la promoción de planes de viviendas de interés social, de sistemas adecuados de financiación ${ }^{35}$, y con la atribución de competencias a los concejos municipales (arts. 313.7 y 330 ).

G) Derecho a la cultura y a la educación. Por lo que se refiere al derecho a la educación el articulo 67 comienza afirmando: «La educación es un derecho de la persona y un servicio público que tiene una función social; con ella se busca el acceso al conocimiento, a la ciencia, a la técnica y a los demás bienes y valores de la cultura...». Derecho a la educación que giraria, en particular, alrededor de los siguientes principios: en primer término, el señalamiento de unos objetivos prioritarios: «La educación formará al colombiano en el respeto a los derechos humanos, a la paz y a la democracia..."; en segundo lugar, la responsabilidad que a este respecto se atribuye al Estado, la familia y la comunidad; en tercer término, la gratuidad de la enseñanza para quienes no puedan sufragarla, así como su obligatoriedad entre los cinco y quince años de edad; en cuarto lugar, la encomendación expresa al Estado de las funciones de inspección y vigilancia.

Derecho a la educación que se completa además con el derecho a crear centros docentes, y el derecho de los padres a elegir el tipo de educación que estimen más conveniente para sus hijos (art. 68). Coherentemente con la naturaleza aconfesional del Estado colombiano se señala también la prohibición de que en los establecimientos del Estado se pueda obligar a recibir educación religiosa.

En cuanto al derecho a la cultura, su reconocimiento constitucional no puede ser asimismo más amplio: «El Estado tiene el deber de promover y fomentar el acceso a la cultura en igualdad de oportunidades...” (art. 70). Y es que no podemos olvidar que nos hallamos ante lo que acertadamente se ha denomindo "Estado de la Cultura» ${ }^{36}$, en cuanto caracterización sobresaliente y principal de la estructura y funciones estatales en la actualidad.

Derechos éstos a la educación y la cultura que se articu-

${ }^{35}$ De idéntica manera, lo recogen los artículos 65 de la Constitución Portuguesa de 1976 y 47 de la Constitución Española de 1978.

${ }_{36}$ Expresión acuñada en el Derecho Constitucional italiano por Spagna Musso, con la publicación de su obra Lo Stato di cultura nella Constituzione italiana, en 1961. 
lan, en particular, a través del ejercicio de «las libertades de enseñanza, aprendizaje, investigación y cátedra» (art. 27), del reconocimiento de la autonomía universitaria - «Se garantiza la autonomia universitaria. Las Universidades podrán darse sus directivas y regirse por sus propios estatutos, de acuerdo con la ley" (art. 69) - , tanto a través de las Universidades públicas como las privadas, asi como con una potenciación especial de las expresiones artísticas, la ciencia y la tecnología (art. 71).

De igual modo, y como complemento a ambos derechos, educación y cultura, el Texto constitucional colombiano prevé también la especial protección por parte del Estado de los bienes de uso público, como es el caso del patrimonio cultural y arqueológico (arts. 8. $^{\circ}$ y 72 ), y de los recursos naturales y el espacio público (arts. 80 y 82). Bienes todos ellos de naturaleza inalienable, imprescriptible e inembargable (art. 63). Materia ésta de competencia compartida entre el Estado central y los propios municipios: «Corresponde a los concejos: $99^{\circ}$ Dictar las normas necesarias para el control, preservación y defensa del patrimonio ecológico y cultural del municipio" (art. 323).

Destacar finalmente, por su peculiaridad, el papel de inspección y vigilancia que a este respecto le atribuye la propia Constitución al Presidente de la República (art. 189.21).

4. Es una Declaración de Derechos que pretende establecer un verdadero y eficaz sistema de tutela de los derechos fundamentales y libertades públicas. A tal efecto, la Constitución de 1991 instaura tanto el principio de la vinculación de los poderes públicos a los diversos derechos y libertades constitucionalmente reconocidos, como un conjunto plural y completo de distintas garantías, fijando de este modo un complejo orden de protección de los mismos.

Asi, y por lo que respecta a la vinculación de los poderes públicos a los derechos reseñados, podemos, de acuerdo con la clásica formulación de la teoria de separación de poderes, señalar sus siguientes maniestaciones:

- En cuanto a la vinculación del Poder Legislativo, el Parlamento (arts. 132 y ss.) se encuentra directamente sometido a la Constitución, en cuanto norma mormarum del ordenamiento jurídico, y garante de los derechos fundamentales y libertades públicas en ellas amparados: "La Constitución es norma de normas. En todo caso de incompatibilidad entre la Constitución y la ley u otra norma jurídica, se aplicarán las disposiciones constitucionales" (art. $4 .^{\circ}$ ). En este sentido, el principio de constitucionalidad se manifiesta específicamente, tanto en la 
necesaria superlegalidad formal de las normas que desarrollan los derechos fundamentales, las denominadas leyes estatutarias (art. 152), como en el control jurisdiccional por parte de la Corte Constitucional cuando las violaciones procedan del Parlamento (art. 242). Y es que, si bien el citado control de constitucionalidad excede el presente ámbito de los derechos y libertades públicas, también es, no obstante cierto, que «el punto de referencia más importante... son los derechos fundamentales» ${ }^{37}$.

- Por lo que respecta a la vinculación del Poder Ejecutivo, ya el artículo $2 .^{\circ}$ del Texto constitucional colombiano realiza la siguiente afirmación de principio: «Las autoridades de la República están instituidas para proteger... (los) derechos y libertades...". De modo más particular, y refiriéndose al Presidente de la República, el artículo 191 señala: "El Presidente de la República..., se obliga a garantizar los derechos y libertades de todos los colombianos».

Vinculación al principio de legalidad que se manifiesta y complementa asimismo con las funciones encomendadas a los gobernadores en los distintos departamentos: «9. Objetar, por inotivos de inconstitucionalidad, ilegalidad o inconveniencia, los proyectos de ordenanza, o sancionarlos y promulgarlos. 10. Revisar los actos de los consejos municipales y de los alcaldes, y, por motivos de inconstitucionalidad o ilegalidad, remitirlos al tribunal competente para que decida sobre su validez» (art. 305). Incluso a los propios alcaldes dentro de su municipio (art. 315.6).

Especial relevancia adquiere también en este ámbito la sumisión expresa de la llamada potestad reglamentaria, recogida en el artículo 189.11 , al principio de legalidad, y su control por parte de los órganos jurisdiccionales (arts. 230 y ss.). A la misma naturaleza ha de responder el control interno que sobre la función administrativa enuncia el artículo 209: «La Administración Pública, en todos sus órdenes, tendrá un control interno que se ejecutará en los términos que señale la ley".

En tercer lugar, y dentro de esta vinculación del Poder Ejecutivo a los derechos y las libertades públicas, podemos destacar además las siguientes manifestaciones: en primer término, a través del papel que en cuanto órganos de control y supervisión de la función ejecutiva y de la actividad administrativa desempeñen tanto la Procuraduría General - «La Procuraduría General de la nación está encargada de la guarda y promoción de los derechos humanos» (art. 118)-, exhortando «al Congreso para que expida las leyes que aseguren la promo-

3i BACHOF: Jueces y Constitución, trad. esp., Madrid 1963, p. 20. 
ción, el ejercicio y la protección de los derechos humanos, y exigir su cumplimiento a las autoridades competentes" (art. 278.4), la Fiscalía General - «La Fiscalia General de la nación está obligada a investigar tanto lo favorable como lo desfavorable al imputado, y a respetar sus derechos fundamentales y las garantias procesales que le asisten” (art. 251)-, como el Defensor del Pueblo, velando «por la promoción, el ejercicio y la divulgación de los derechos humanos» (arts. 117 y 282).

Finalmente resaltar por su importancia los artículos 218 y 222 con respecto a los fines y las atribuciones a desarrollar por la policia, primando la defensa y salvaguardia de los derechos fundamentales y libertades. Dice el artículo 222: “... En las etapas de formación, se les impartirá la enseñanza de los fundamentos de la democracia y de los derechos humanos» ${ }^{38}$.

- En cuanto a la vinculación del Poder Judicial, y dejando al margen el análisis particular de las garantías jurisdiccionales que amparan los derechos fundamentales y las libertades públicas que examinaremos inmediatamente, el artículo 231 realiza ya un reconocimiento, aunque indirecto, de la mencionada vinculación. Asi señala el artículo 231: "Los jueces, en sus providencias, sólo están sometidos al imperio de la ley. La equidad, la jurisprudencia, los principios generales del derecho y la doctrina son criterios auxiliares de la actividad judicial» ${ }^{39}$.

Especialisima trascendencia reviste asimismo la competencia expresa asignada a la jurisdicción constitucional de "revisar, en la forma en que determine la ley, las decisiones judiciales relacionadas con la acción de tutela de los derechos fundamentales» (art. 239.9).

\section{Garantías de los Derechos fundamentales y libertades públicas}

Expuesta la vinculación de los Poderes Legislativo, Ejecutivo y Judicial, detengámonos pues, finalmente, en el análisis de sus garantías. Examen de las garantías que podemos agrupar en los siguientes grupos ${ }^{40}$ :

38 El artículo 104.1 de la Constitución Española de 1978 se manifiesta de modo semejante: "Las Fuerzas y Cuerpos de seguridad, bajo la dependencia del Gobierno, tendrán como misión proteger el libre ejercicio de los derechos y libertades y garantizar la seguridad ciudadana».

${ }_{39}$ De idéntico modo el artículo 117.1 de la Constitución Española de 1978 señala: «La justicia emana del pueblo y se administra en nombre del Rey por Jueces y Magistrados integrantes del Poder Judicial, independientes, inamovibles, responsables y sometidos únicamente al imperio de la ley".

40 Seguimos la clasificación que con respecto a la Constitución Española de 1978 se recoge en De EsTeBAN y LoPEZ GueRRA: op. cit., pp. 212 y ss. 
A) Garantías Previas. Es decir, aquellas que, aun no siendo propias y exclusivas de los derechos fundamentales y libertades públicas, representan «las condiciones mínimas exigidas para que pueda hablarse de vigencia de los derechos fundamentales y por tanto de Estado democrático; sólo si se dan unas determinadas circunstancias estructurales en una sociedad política ésta puede calificarse de democrática, de ahi el carácter previo que de estas garantías se predica" ${ }^{41}$.

Garantias que se desglosan, tanto en la satisfacción y el respeto de las notas definitorias que caracterizaban el denominado Estado Liberal de Derecho (división de poderes, imperio de la ley, sumisión de la actividad administrativa al principio de legalidad, y amparo de los derechos fundamentales y las libertades públicas), cuanto el reconocimiento del Estado colombiano como un Estado Social (art. $1 .^{\circ}$ ). Es decir, «la convicción de que la libertad política, sin determinadas condiciones sociales, económicas y culturales que constituyen el segundo bloque de estas garantías, lleva en definitiva a una sociedad injusta" ${ }^{42}$. A tal necesidad responde la constitucionalización examinada de los llamados derechos económicos y sociales que ampara el Capitulo 2 del Título II «Derechos Sociales, Económicos y Culturales».

B) Garantias de Procedimiento. Dichas garantias pretenden determinar de un modo especial el más adecuado desarrollo legislativo de que han de disfrutar los derechos y las libertades públicas. A este respecto, la Constitución colombiana de 1991 reviste la siguiente peculiaridad: el establecimiento de una superlegalidad de las normas que desarrollan los mentados derechos fundamentales. Superlegalidad que se instrumenta a través de las denominadas "leyes estatutarias" que recoge el articulo 152 del Texto constitucional: «Mediante las leyes estatutarias, el Congreso de la República regulará las siguientes materias: a) Derechos y deberes fundamentales de las personas y los procedimientos y los recursos de protección...". Leyes estatutarias que se caracterizan frente a las leyes ordinarias por los requisitos establecidos en el artículo 153: «La aprobación, modificación o derogación de las leyes estatutarias exigirá la mayoría absoluta de los miembros del Congreso y deberá efectuarse dentro de una sola legislatura. Dicho trámite comprenderá la revisión previa por parte de la Corte Constitucional, de la exigibilidad del proyecto. Cualquier ciudadano podrá intervenir para defenderla o impugnarla» ${ }^{43}$.

43 La Constitución Española de 1978, inspirándose en el constitucionalismo fran- 
En segundo lugar, la reseñada superlegalidad se complementa con el principio de reserva de ley, que la Constitución menciona además expresamente con referencia a algunos de los derechos y las libertades públicas enumerados. Así, y entre otros, con respecto a la inviolabilidad de la correspondencia y demás formas de comunicación privada (art. 15), el derecho a la honra (art. 21), el ejercicio del derecho de petición ante organizaciones de naturaleza privada (art. 23), la atribución de funciones a los colegios profesionales (art. 26), las garantías de la libertad personal (art. 28), las garantías procesales (art. 29), el ejercicio del derecho de asilo (art. 36), los derechos de reunión y asociación (arts. 37 y 38), en materia de matrimonio y protección de la familia (art. 42) y de la infancia (art. 44), en la protección de la salud (art. 49), en la fijación del Estatuto del trabajo (art. 53), en el derecho de negociación colectiva (art. 55), en el derecho de huelga (art. 56), en materia de Seguridad Social (art. 48), en el derecho de propiedad (arts. 58 y ss.), en el régimen de las donaciones intervivos o testamentarias (art. 62), en materia de creación de centros docentes (art. 68), en el derecho de autonomía universitaria (art. 69), en la recuperación del patrimonio cultural (art. 72), en el derecho de acceso a los documentos públicos (art. 74), en el uso del espacio electromagnético (art. 75) y televisión (art. 76), así como en los derechos del medio ambiente (art. 79).

Principio de reserva de ley enunciado que, aunque la Constitución colombiana, a diferencia por ejemplo del artículo 19.2 de la Ley Fundamental de Bonn de 1949 y del artículo 53 de la Constitución Española de 1978, no lo menciona expresamente, hay que entender que se concreta en la protección del "contenido esencial» de los diversos derechos y las libertades públicas. Así, y respecto de tal contenido, se trata de hacer posible que los particulares puedan alcanzar los intereses prote-

cés, acuña la categoria de las denominadas leyes orgánicas en su artículo 81: "1. Son leyes orgánicas las relativas al desarrollo de los derechos fundamentales y de las libertades públicas, las que aprueben los Estatutos de Autonomia y el régimen electoral y las demás previstas en la Constitución.

2. La aprobación, modificación o derogación de las leyes orgánicas exigirá mayoria absoluta del Congreso, en una votación final sobre el conjunto del proyecto».

La denominación de leyes orgánicas se utiliza, en cambio, por la Constitución Colombiana de 1991 con un sentido y un contenido diferentes. Dice el articulo 151: «EI Congreso expedirá leyes orgánicas a las cuales estará sujeto el ejercicio de la actividad legislativa. Por medio de ellas se establecerán los reglamentos del Congreso y de cada una de las Cámaras, las normas sobre preparación, aprobación y ejecución del presupuesto de rentas y ley de apropiaciones y del plan general de desarrollo, y las relativas a la asignación de competencias normativas a las entidades territoriales. Las leyes orgánicas requerirán, para su aprobación, la mayoría absoluta de los votos de los miembros de una y otra Cámara". 
gidos por el Derecho Constitucional: «Cualquier limitación a un derecho fundamental en favor de los intereses estatales dificulta el logro de aquellos intereses particulares. Pero si la limitación va tan lejos que los particulares no pueden de ninguna manera lograr sus intereses protegidos por el derecho fundamental... es, por tanto, inconstitucional» ${ }^{44}$.

Necesidad de tutela que adquiere, lógicamente, especial relevancia en los supuestos de los estados de excepción (Estado de Guerra Exterior (art. 212), Estado de Conmoción Interior (art. 213) y Estado de Emergencia (art. 215)). A tales efectos el artículo 214.2 señala: «No podrán suspenderse los derechos humanos ni las libertades fundamentales. En todo caso se respetarán. las reglas del derecho internacional humanitario. Una ley estatutaria regulará las facultades del gobierno durante los estados de excepción y establecerá los controles judiciales y las garantias para proteger los derechos, de conformidad con los tratados internacionales. Las medidas que se adopten deberán ser proporcionales a la gravedad de los hechos». Y en el artículo 218 , en su apartado sexto, se prevé también la intervención de la Corte Constitucional en el control de los decretos legislativos promulgados durante los mencionados estados de anormalidad política.

Asimismo se prohibe la regulación en materia de derechos y libertades fundamentales por parte del Poder Ejecutivo. Así se recoge expresamente en el artículo 150.10 del Texto constitucional, cuando, estableciendo la facultad del Presidente de la República de dictar decretos con fuerza de ley, se precisa, no obstante, el alcance de su ámbito material: «Estas facultades no se podrán conferir para expedir códigos, leyes estatutarias...”.

Finalmente, y aunque con un alcance indirecto, habría que hacer referencia a los mecanismos de reforma constitucional del Título XIII de la Constitución, característicos de un Texto constitucional, como el colombiano, de naturaleza rígida (arts. 374 y ss.). Y en especial agravadísimo, en el supuesto de los derechos reconocidos en el Capítulo 1 del Titulo I (art. 377).

C) Garantias de Control y Fiscalización: las Comisiones Parlamentarias y el Defensor del Pueblo. En cuanto a las primeras, si bien se constituyen y despliegan funciones que no se circunscriben exclusivamente al ámbito de los derechos fundamentales y las 
libertades públicas, cobran especial relevancia y significado cuando recaen sobre éstos. En este sentido dice el artículo 137: "Cualquier comisión permanente podrá emplazar a toda persona natural o jurídica, para que en sesión especial rinda declaraciones orales o escritas, que podrán exigirse bajo juramento, sobre hechos relacionados directamente con indagaciones que la comisión adelante» ${ }^{45}$.

Por lo que se refiere a la figura del Defensor del Pueblo, el denominado Ombudsman en los países nórdicos, se configura en la línea más tradicional en el Derecho comparado, "como una magistratura de simple persuasión a la que sólo excepcionalmente se confien otros poderes que no sean los de indigar y señalar a las autoridades competentes los casos que merecen ser revisados o las medidas a adoptar" ${ }^{46}$. De este modo aparece pues como respuesta a la hipertrofia de la Administración contemporánea y a su creciente burocratización, que la hace, de hecho, el origen de las violaciones más frecuentes de los derechos y libertades públicas en la actualidad ${ }^{47}$.

En cuanto a su reconocimiento se encuentra recogido en el artículo 281: «El Defensor del Pueblo formará parte del Ministerio Público y ejercerá sus funciones bajo la suprema dirección del Procurador General de la Nación. Será elegido por la Cámara de Representantes para un periodo de cuatro años de terna elaborada por el Presidente de la República». Por lo que se refiere a sus funciones, ya apuntadas en el artículo 117, éstas no pueden ser más significativas: $\ll 1$. ... Orientar e instruir a los habitantes del territorio nacional y a los colombianos en el exterior en el ejercicio y defensa de sus derechos ante las autoridades competentes o entidades de carácter privado. 2. Divulgar los derechos humanos y recomendar las políticas para su enseñanza. 3. Invocar el derecho de Habeas Corpus e interponer las acciones de tutela, sin perjuicio del derecho que asiste a los interesados" (art. 282) ${ }^{48}$.

45 De modo parecido, por ejemplo, el articulo 76.1 de la Constitución Española de 1978 manifiesta: «El Congreso y el Senado, y, en su caso, ambas Cámaras conjuntamente, podrán nombrar Comisiones de investigación sobre cualquier asunto de interés público. Sus conclusiones no serán vinculantes para los Tribunales, ni afectarán a las resoluciones judiciales, sin perjuicio de que el resultado de la investigación sea comunicado al Ministerio Fiscal para el ejercicio, cuando proceda, de las acciones oportunas".

46 LA PERGOLA: "Ombudsman y Defensor del Pueblo: apuntes para una investigación comparada», Revista de Estudios Políticos, núm. 7, 1979, p. 75.

${ }_{47}$ Sobre dicha figura, y entre otros estudios, GIL ROBLES: EI Defensor del Pueblo, Madrid 1979.

${ }_{48}$ El articulo 54 de la Constitución Española de 1978 señala: «Una ley orgánica regulará la institución del Defensor del Pueblo, como alto comisionado de las Cortes Generales, designado por éstas para la defensa de los derechos comprendidos en este Título, a cuyo efecto podrá supervisar la actividad de la Administración, dando cuenta a las Cortes Generales". 
D) Garantías Jurisdiccionales. Las garantías jurisdiccionales cierran el examen que hemos realizado de los derechos fundamentales y libertades en la Constitución colombiana de 1991, representando además, y con toda seguridad, las más perfeccionadas y eficaces de todas cuantas hemos señalado. Garantías jurisdiccionales que hallan su último fundamento y justificación «en el derecho al proceso" y en la tutela de las diversas "garantías procesales amparadas constitucionalmente" (art. 29), así como en el reconocimiento del «acceso a la justicia» que establece el artículo 239. Dice el artículo 239: «Se garantiza el derecho de toda persona a acceder a la administración de la justicia» ${ }^{49}$.

Su regulación constitucional concreta y específica se recoge, no obstante, en el Capítulo 4 del Título II «De la Protección y Aplicación de los Derechos", donde se señalan dos grandes vias de protección. Una primera, 'de carácter general y no exclusiva de los derechos fundamentales y libertades públicas; otra, en cambio, de naturaleza restringida y limitada a una serie bien determinada y definida de derechos y libertades.

Así, y en cuanto a la primera, el artículo 87 señala: «Toda persona podrá acudir ante la autoridad judicial para hacer efectivo el cumplimiento de una ley o de un acto administrativo. En caso de prosperar la acción, la sentencia ordenará a la autoridad reunente el cumplimiento del deber omitido". Y el artículo 90 dice: «... la ley establecerá los demás recursos, acciones y procedimientos necesarios para que puedan propugnar por la integridad del orden jurídico, y la protección de sus derechos individuales, de grupo o colectivos, frente a la acción u omisión de las autoridades públicas». Dentro de ella se hace mención expresa de la jurisdicción contencioso-administrativa (art. 239) y de las jurisdicciones especiales (arts. 248 y 249).

Por lo que respecta a la segunda, el artículo 86 establece un procedimiento específico de protección, la acción de tutela, con un ámbito material de aplicación bien delimitado: los derechos consagrados en los artículos $11,12,13,14,15,16,17,18$, $19,20,21,22,23,24,26,27,28,29,30,31,33,34,37$ у 40.

Acción de tutela que se articula, frente al procedimiento genérico antes enunciado, como un procedimiento de carácter preferente y sumario: «Toda persona tendrá acción de tutela pa-

49 El artículo 24.1 de la Constitución Española de 1978, entendemos, que de un modo más perfeccionado que en el Texto constitucional colombiano, dice: "Todas las personas tienen derecho a obtener la tutela efectiva de los jueces y tribunales en el ejercicio de sus derechos e intereses legitimos, sin que, en ningún caso, pueda producirse indefensión'". 
ra reclamar ante los jueces, en todo momento y lugar, mediante un procedimiento preferente y sumario, por sí misma o por quien actúe en su nombre, la protección inmediata de sus derechos constitucionales fundamentales, cuando quiera que éstos resulten vulnerados o amenazados por la acción o la omisión de cualquier autoridad pública...» (art. 86). Acción de tutela subordinada, no obstante, a un límite de ejercitabilidad: «Esta acción de tutela sólo procederá cuando el afectado no disponga de otro medio de defensa judicial, salvo que dicha acción se utilice como mecanismo transitorio para evitar un perjuicio irremediable..." (art. 86).

En cuanto al carácter y contenido de su ámbito de protección, el «fallo, que será de inmediato cumplimiento, podrá impugnarse ante el juez competente $y$, en todo caso, lo remitirá a la Corte Constitucional para su revisión» (art. 86).

Sin embargo, y junto a estas dos garantias jurisdiccionales desplegadas por los órganos judiciales ordinarios, habrá asimismo que resaltar la competencia por primera vez de la jurisdicción constitucional en esta materia de protección de los derechos y las libertades fundamentales. Así, y en cuanto al amparo de los derechos fundamentales, el artículo 241 señala: «A la Corte Constitucional se le confia la guarda de la integridad y supremacía de la Constitución, en los estrictos y precisos términos de este articulo. Con tal fin, cumplirá las siguientes funciones: "4. Decidir sobre las demandas de inconstitucionalidad que presenten los ciudadanos contra las leyes, tanto por su contenido material como por vicios de procedimiento en su formación (acción popular de inconstitucionalidad). 5. Decidir sobre las demandas de inconstitucionalidad que presenten los ciudadanos contra los decretos con fuerza de ley dictados por el gobierno, con fundamento en los artículos 150 numeral 10 y 341 de la Constitución por su contenido material o por vicios de procedimiento en su formación. 7. Decidir definitivamente sobre la constitucionalidad de los decretos legislativos que dicte el gobierno, con fundamento en los artículos 212,213 y 215 de la Constitución. 8. Decidir definitivamente sobre la constitucionalidad de los proyectos de ley que hayan sido objetados por el Gobierno como inconstitucionales, y de los proyectos de ley estatutarios, tanto por su contenido material como por vicios de procedimiento en su formación. 9. Revisar, en la forma que lo determine la ley, las decisiones judiciales sobre la tutela de los derechos constitucionales"»50.

50 El artículo 161 de la Constitución Española de 1978 atribuye a la jurisdicción constitucional las siguientes competencias: 
Garantías que se complementan con el papel asignado al Consejo de Estado en las funciones contencioso-administrativas, y en las residuales no encomendadas a la Corte Constitucional (art. 237.1 y 2 ).

Finalmente se prevé el ejercicio de las acciones populares, con incidencia también en materia de protección de derechos y libertades fundamentales - "La ley regulará las acciones populares para la protección de los derechos e intereses colectivos..." ${ }^{51}$-, las "acciones originadas en los daños ocasionados a un número plural de personas, sin perjuicio de las correspondientes acciones particulares", así como «los casos de responsabilidad civil objetiva por el daño inferido a los derechos e intereses colectivos" (art. 88). Ordenación que se culmina asimismo con la apelación a los postulados de la buena fe en la actuación de los particulares y de las autoridades públicas (art. 91), la exención de responsabilidad por mandato superior, con excepción de los militares en los casos de manifiesta infracción de un precepto constitucional (art. 91), la responsabilidad patrimonial del Estado por los daños antijurídicos causados por acción u omisión de sus autoridades (art. 90), la facuiltăd de cualquier persona natural o jurídica de solicitar «la aplicación de las sanciones o disciplinarias derivadas de la conducta de las autoridades públicas (art. 92), así como la prohibición de establecer o exigir permisos, licencias o requisitos adicionales para el ejercicio de los derechos, cuando éstos se han reglamentado de un modo general (art. 84).

\section{Es una Declaración orientada hacia el imparable proceso de}

«1. El Tribunal Constitucional tiene jurisdicción en todo el territorio español y es competente para conocer:

a) Del recurso de inconstitucionalidad contra leyes y disposiciones normativas con fuerza de ley. La declaración de inconstitucionalidad de una norma juridica con rango de ley, interpretada por la jurisprudencia, afectará a ésta, si bien la sentencia o sentencias recaídas no perderán el valor de cosa juzgada.

b) Del recurso de amparo por violación de los derechos y libertades referidos en el artículo 53.2 de este Constitución, en los casos y formas que la ley establezca.

c) De las demás materias que le atribuyan la Constitución o las leyes orgánicas.

2. El Gobierno podrá impugnar ante el Tribunal Constitucional las disposiciones y resoluciones adoptadas por los órganos de las Comunidades Autónomas. La impugnación producirá la suspensión de la disposición o resolución recurrida, pero el Tribunal, en su caso, deberá ratificarla o levantarla en un plazo no superior a cinco meses».

Competencias que se pormenorizan en cuanto a su ejercicio y procedimiento en la Ley Orgánica 2/1979, de 3 de octubre.

51 El artículo 125 de la Constitución Española de 1978 señala: «Los ciudadanos podrán ejercer la acción popular y participar en la Administración de Justicia mediante la institución del Jurado, en la forma y con respecto a aquellos procesos penales que la ley determine, así como en los Tribunales consuetudinarios y tradicionales». 
internacionalización que viven en la actualidad los derechos fundamentales y libertades públicas. Internacionalización que se vislumbra, tanto en la prevalencia de los convenios internacionales suscritos sobre el derecho interno, como por lo que respecta al sentido de interpretación de la Carta de Derechos examinada. Así señala el artículo 93: "Los Tratados y Convenios internacionales ratificados por el Congreso, que reconocen los derechos humanos y que prohiben su limitación en estado de excepción, prevalecen en el orden interno". $Y$ en cuanto a la debida interpretación, en el sentido por éstos fijada, el mentado artículo 93 continúa manifestando: «Los derechos y deberes consagrados en esta Carta se interpretarán de conformidad con los tratados internacionales sobre derechos humanos ratificados por Colombia».

Aplicación e interpretación que reviste en todo caso especial significación en la protección de la infancia - "Gozan también de los demás derechos consagrados en la Constitución, en las leyes y en los tratados internacionales suscritos por Colombia» - 52 , y en materia laboral - «Los Convenios Internacionales del trabajo debidamente ratificados, hacen parte de la legislación interna» (art. 53).

Corolario todo ello, del expreso "reconocimiento de los principios del derecho internacional aceptados por Colombia" (art. $\left.9^{\circ}\right)$, y de la prioridad en el trámite parlamentario «de los proyectos de ley aprobatorios de los tratados sobre derechos humanos que sean sometidos a su consideración (al Congreso) por el Gobierno" (art. 164).

52 El artículo 10.2 de la Constitución Española de 1978 expresa: «Las normas relativas a los derechos fundamentales y libertades que la Constitución reconoce se interpretarán de conformidad con la Declaración Universal de Derechos Humanos y los tratados y acuerdos internacionales sobre la misma materia ratificados por España". 